\title{
EL MODELO BRITÁNICO DE NOMBRAMIENTOS JUDICIALES: «JUDICIAL INDEPENDENCE IN LAW»
}

\author{
ROSA MARÍA FERNÁNDEZ RIVEIRA \\ Profesora Titular de Derecho Constitucional \\ Universidad Complutense
}

\begin{abstract}
SUMARIO
I. Introduccion II. La reforma constitucional británica: Constitutional Reform Act de 2005 una reforma ambiciosa III. El viejo modelo de nombramientos judiciales: «...Tap on shoulder and secret soundings» IV. Nuevo diseño: la Judicial Appointments Commission (JAC) de 2006. V. La participacion de la JAC en los nombramientos de jueces al Tribunal Supremo del Reino Unido VI. A modo de conclusión: el activo y novedades del nuevo modelo inglés JAC tras más de diez años de experiencia
\end{abstract}

«...Frankly, I'm personally fed up with having to deal with a situation where Parliament debates issues and the judges then overturn them.» (Blunkett D., $2003)^{1}$

\section{INTRODUCCIÓN}

El siglo veintiuno está siendo un periodo de profundos retos e impensables cambios. La clave internacional, para entender el derecho constitucional y, desde

1 La Reforma Constitucional Británica de 2005 supuso y supone una revolución importante para el Reino Unido en su configuración clásica democrática, no sólo porque afecta de lleno al Poder Judicial, sino porque rediseña las relaciones entre los tres poderes clásicos: legislativo, ejecutivo y Judicial. El papel de los Jueces ha ido cambiando y el principio de «soberanía parlamentaria» ha sufrido tales cambios también. En el año 2003 un miembro de la Cámara de los Comunes, D. BLUNKETT explicaba que conceder a los Jueces, tras la HRA Human Rights Act de 1998, más poder, por ejemplo, el de declarar inconstitucionales ciertas leyes aprobadas por el Parlamento generaría, sin duda, un mayor sentimiento contrario a ellos: «anti-judicial review...». De ahí que dijera abiertamente que estaba harto de encontrarse asiduamente con situaciones en las que lo hecho y aprobado por el Parlamento era después «modificado por los Jueces»; Le Suer A., «Imagining judges in a written UK Constitution»; U.K. Constitutional Blog, 14 May 2014; 
luego el derecho público, era ya una verdad a voces a finales del siglo veinte. Hoy debemos aceptar, que si bien es cierto que existe un constitutional heritage común a la gran mayoría de regímenes democráticos, fuente inagotable de «legitimidad»; también lo es, que ciertos principios constitucionales clásicos andan necesitados de adaptaciones y, en no pocos, casos de reformas y que éstas deben ser abordadas por cada Estado de manera personal e intransferible.

El principio de representación ha cambiado, como decía Pitkin: ¿cuándo han de sentir los hombres que son representados? ¿Cuándo sería correcto decir que son representados? ¿Qué valdría como evidencia de que son representados?² ¿Qué es una representación de calidad? El desgaste de las instituciones, las nuevas demandas y necesidades sociales y/o políticas, la irrupción de realidades como las «Nuevas Tecnologías» impregnando a las nuevas generaciones, los nuevos modelos de partidos políticos, son algunos de los factores a considerar en el contexto de cualquier sistema jurídico.

Vernon Vogdanor señala que desde 1997 asistimos a una verdadera «era» de «reforma constitucional». ${ }^{3}$

El Reino Unido, cuna del parlamentarismo, autor del principio de soberanía parlamentaria, laboratorio de un bipartidismo puro (hoy denostado también) con una vetusta Constitución no escrita, enfrenta y afronta un momento complicado y cambiante. Dicey señalaba que al abrigo del principio de soberanía parlamentaria, esencia de esa Constitución no escrita, sólo Westminster podría hacer y deshacer leyes ${ }^{4}$. Junto a este principio, pilar complementario del rule of law, sólo los Tribunales (los Jueces) deberían asegurar y garantizar el cumplimiento de la ley por los demás poderes públicos. Y la grandeza de tal función debería desarrollarse de manera independiente de cualquier otro poder.

Una independencia judicial, durante muchos años, bajo un diseño institucional (el anterior a la reforma de 2005), más que «provocador». Lord Chancellor, Ministro de Justicia en el ejecutivo, al mismo tiempo la primera y máxima autoridad dentro de la Judicatura británica (Head of Judiciary) y también Speaker de la Cámara de los Lores. A su vez, ciertos Lores miembros de la Cámara Alta (House of Lords), eran simultáneamente Jueces (Law Lords) en el Appellate Committe of the House of Lords (hoy en día el Tribunal Supremo del Reino Unido). Una mixtura de ejecutivo, legislativo y judicial, más que estridente.

2 Pitkin H. F., El concepto de representación, Centro de Estudios Constitucionales, Madrid 1985.

3 «The reforms include the independence of the Bank of England; devolution; proportional representation for election of devolved bodies and for the European Parliament; the Human Rights Act; the Freedom of Information Act; and measures involving reform of the House of Lords. The CRA continued that trend, by fundamentally altering the historic office of the Lord Chancellor and paving the way for the removal of the law lords from the House of Lords and the creation of a Supreme Court...», en «Our New Constitution», Law Quarterly Review 120, 2004, pp. 241 y ss.

4 Lord Irvine Of LAIRg, Sovereignty in Comparative perspective: constitutionalism in Britain and America, in Human Rights, Constitutional Law and the Development of the English Legal system: Selected essays 227, 2003, pp. 229 y ss. 
Muchos autores justificaron y razonaron lo irrazonable, Skold M., explicaba cómo la independencia judicial conseguía mantenerse a flote en el Reino Unido a lo largo de los años bebiendo de heterogéneos factores: la existencia de una titularidad de por vida mientras dure el buen comportamiento (Good behaviour), la fijación de los salarios por el Parlamento y no por el gobierno, la inmunidad respecto de los procesos civiles, el acuerdo convencional de los Jueces (Law Lords) de no ejercer sus funciones legislativas en la Cámara tratando de mantenerse al margen de las decisiones políticas, la clara abstención o contención de los miembros del ejecutivo y, en cierto modo, del legislativo no criticando las decisiones judiciales $^{5}$, etc. Todo ello contribuía a la supervivencia de una independencia judicial amenazada de muerte en su diseño institucional.

El Reino Unido está viviendo la crisis constitucional más relevante desde la restauración de la Monarquía en 1660 y como ha descrito Bogdanor, la soberanía popular expresada en el referéndum del Brexit se enfrenta a la soberanía parlamentaria de Westminster ${ }^{6}$. Prueba de ello fue la Sentencia Miller contra el Estado, (Tribunal Supremo del Reino Unido 2017 en el asunto del Brexit ${ }^{7}$ ). El gobierno, dice el alto tribunal, deberá contar con el Parlamento para interponer y gestionar la salida de la Unión Europea, de lo contrario, el ejecutivo podría estar disponiendo sobre Derechos fundamentales de los ciudadanos regulados y protegidos por leyes del Parlamento. ${ }^{8}$

Y también, recientemente, el 24 de septiembre de 2019 el TS británico en el asunto Cherry, Miller v. The Prime Minister, sobre el cierre largo del Parlamento, ha vuelto a defender sin paliativos, la soberanía parlamentaria de nuevo cuestionada.

Los hechos revelan que reflexiones previsibles a la luz de los principios clásicos, empiezan a resquebrajarse. ¿Dónde está y dónde podemos identificar la Constitución inglesa no escrita? Cada vez se hace más difícil. La Human Rights Act de 1998 trasladando a derecho doméstico inglés el significado de haber ratificado la Convención Europea de Derecho Humanos y respetando su jurisdicción en Estrasburgo; el tortuoso proceso de la Devolution empoderando a Escocia e Irlanda del Norte en la tramitación de sus asuntos; la reforma de la House of Lords en 1999, gigantesca e inmanejable cámara alta dotada de competencias injustificables; la Fixed-term Parliament Act de 1911, recuperando estabilidad y evitando disoluciones anticipadas de la legislatura parlamentaria; el difícil referéndum

5 SKold M. «The Reform Act's Supreme Court: a missed opportunity for Judicial Review in the United Kingdom», CONN. L. REV., 2007, pp. 2149 y ss.

6 Bogdanor V., Beyond Brexit: Towards a British Constitution, I.B. Tauris, United Kingdom 2019; pp. 31 y ss.

7 Miller vs. Secretary of State for exiting the European Union (appellant) https://www.supremecourt.uk/ cases/docs/uksc-2016-0196-judgment.pdf

8 Virgala Foruria E., La Constitución británica en el Siglo xxi. Soberanía parlamentaria, constitucionalismo Common law y leyes constitucionales, Marcial Pons 2018, pp. 26 y 27. 
sobre Escocia en 2014 o el referéndum del Brexit de 2016, son realidades que erosionan una Constitución escurridiza y ambigua a pesar de su longevidad.

Y si es cierto como dice McHarg que una constitución no debe reducirse y empobrecerse a un solo texto escrito. No lo es menos que, el silencio de un texto constitucional «no codificado» puede ser una amenaza en los tiempos descritos 9 suscitando demasiadas e irreconciliables interpretaciones.

En este agitado escenario Reino Unido aprobaba en 2005 una importante reforma a través de la Constitutional Reform Act. A ella nos vamos a dedicar en las páginas de este trabajo, porque de ella se dice que dibuja un modelo judicial distinto y un nuevo procedimiento para nombrar a los jueces. El viejo modelo judicial británico era oscuro, informal, cerrado y consensuado con el poder ejecutivo. Jueces y políticos entendían de manera estrecha y, ciertamente opaca, el concepto de «independencia judicial» en un sistema de common law.

El poder judicial hoy está regulado en una ley (Constitutional Reform Act), precedente impensable en un país de cultura jurídica common law. Responde a un diseño formal, burocratizado, con una gestión administrativa interna compleja. Y, sobre todo, se articula en torno a un esquema de fragmentación (separación) del poder, esto es, se ha expulsado al ejecutivo del judicial y se ha reforzado el autogobierno de éste, dotándole de nuevas estructuras administrativas, más competencias y elevadas dosis de publicidad, formalismo y transparencia ${ }^{10}$. Los retos del nuevo modelo judicial serán la diversidad y mayor representatividad de la Judicatura.

Las páginas siguientes se centran en explicar cómo está funcionando y qué frutos está produciendo esta ambiciosa reforma. Para ello explicaremos el contenido de la misma partiendo del viejo y oscuro modelo judicial y sus «agujeros negros».

\section{LA REFORMA CONSTITUCIONAL BRITÁNICA, CONSTITUTIONAL REFORM ACT DE $2005^{11}$, UNA REFORMA AMBICIOSA}

Sortear qué es y dónde está la Constitución del Reino Unido, no es tarea fácil. Griffith, desempolvando viejas teorías de Grimm, reconocía que la Constitución británica no es una Constitución en sentido normativo, es más bien un concepto descriptivo que refleja las condiciones políticas que, en realidad, prevalecen [...] en un momento determinado, dando cuerpo a la suma de relaciones entre ley y poder ${ }^{12}$.

9 Mcharg Aileen, «Reforming the United Kingdom Constitution: Law, Convention, Soft Law.», 71 Mod. L. Rev. 853 (2008)

10 Graham G., Hazell R., Malleson K., O'Brien P., The Politics of Judicial Independence in the UK's Changing Constitution, Cambridge University Press, United Kingdom 2015, pp. 252 y ss.

11 https:/www.legislation.gov.uk/ukpga/2005/4/introduction

12 «...Constitution in the first sense of the word refers to the nature of a country with reference to its political conditions. Constitution in the second sense refers to a law that concerns itself with the 
El 23 de junio de 2016 tuvo lugar en el Reino Unido el referéndum sobre el Brexit ${ }^{13}$. Sólo diez años antes del referéndum, esto es, el 24 de marzo de 2005 se publicaba la Constitutional Reform Act, una ley trascendental de naturaleza y rango constitucional en un modelo de unwritten constitution. En otras palabras, una profunda reforma articulando nuevas herramientas en aras de un objetivo esencial: garantizar la independencia judicial. El Departamento de asuntos constitucionales del Reino Unido ${ }^{14}$, a través de su comisión en el Parlamento de Westminster, definiría esta vital reforma como una nueva manera de diseñar las relaciones entre el ejecutivo y judicial (y la Judicatura en general) en el siglo XxI.

En el Reino Unido, la Independencia Judicial ha sido un «rasgo definidor» de su esencia constitucional, piedra angular (cornerstone) de su rule of law. Y, paradójicamente, nunca se ha establecido reconocimiento normativo de la independencia judicial ${ }^{15}$. La primera vez que se otorga voz normativa a ésta será a través de la Constitutional Reform Act de 2005 (en adelante CRA).

Un informe de la Cámara de los Comunes explicaba que la CRA de 2005, en caso de tener una Constitución codificada, sería, entre otras cosas, «Judicial Independence in law» ${ }^{16}$

Los contenidos esenciales de la CRA de $2005^{17}$ son:

a) la modificación de la oficina del Ministro de Justicia [Lord Chancellor: LC], en sus competencias y funciones; Ahora y tras esta importante reforma quedará relegado a sus funciones ejecutivas en el Gobierno perdiendo sus competencias legislativas y judiciales ${ }^{18}$.

establishment and exercise of political rule. Consequently, the first definition refers to an empirical or descriptive constitution and the second a normative and prescriptive concept. Used empirically, constitution reflects the political conditions that in fact prevail in a specific region at a given time. In the normative sense, constitution establishes the rules by which political rule should be exercised under law...», GRIFFITH J.A.G., «The Political Constitution», MLR Modern Law Review, n. ${ }^{\circ} 42$, January 1979, pp. 1-21;

$1351,9 \%$ (17.410,742 votos) votaron salir de la UE, frente a 48,1\% (16.141,242 votos) que preferían permanecer en la UE. La participación fue del 70,2\% de un censo de 46.501,241 votantes. http://www.bbc. com/news/politics/eu_referendum/results

14 Department for Constitutional Affairs, Constitutional Reform: A Supreme Court for the United Kingdom, July 2003, CP11/03;

15 Woodhouse D., «United Kingdom, The Constitutional Reform Act 2005 —defending Judicial Independence the English way», I-CON, Vol. 5, n. ${ }^{\circ}$ 1, 2007, pp. 153 y 154.

16 House of Commons Report, Political and Constitutional Reform Committee, Constitutional role of the Judiciary if there were a codified constitution, Fourteenth Report of Session 2013-14, 14 MY 2014; https://publications.parliament.uk/pa/cm201314/cmselect/cmpolcon/802/802.pdf

17 Delaney E., «Searching for constitutional meaning in institutional design: The debate over Judicial appointments in the United Kingdom», in I-CON, vol. 14, n. ${ }^{\circ}$ 3, 2016, pp. 752 y ss.

18 Lord Mackay, «The Lord Chancellor's Role within Government», New Law Journal n. ${ }^{\circ} 145$, 1995 , pp. 1651 y ss. «... The new-style Lord Chancellor occupies a much pared-down post: no longer Speaker of the House of Lords and no longer a Judge. [... The office of the new-style Lord Chancellor is now a conventional ministerial office with a heavyweight portfolio: we've gone from a Lord Chancellor's Department that was about six men and a dog to a Ministry or Justice now that's a major government department...», Graham G., Hazell R., Malleson K., O’brien P, op. cít. pp. 34. 
b) la creación del Tribunal Supremo del Reino Unido (2009) suprimiendo la Court of Appeal de la House of Lords (Tribunal de Apelación de la Cámara de los Lores), órgano judicial supremo del viejo modelo.

c) la nueva jurisdicción del Judicial Committe of the Privy Council ${ }^{19}$ y las nuevas funciones en materia judicial del Presidente del Consejo.

d) Y, por último, la creación en 2006 de un nuevo procedimiento de nombramiento de los Jueces atribuido a un órgano público de naturaleza administrativa: la Judicial Appointment Commission (en adelante JAC).

Una auténtica revolución constitucional que remueve, para empezar, el andamiaje de la clásica separación de poderes británica.

El 1 de abril de 2003 la Asamblea Parlamentaria del Consejo de Europa a través del Comité de Asuntos Legales y Derechos Humanos adoptaba unánimemente una clara Resolución para la oficina de Lord Chancellor en el Reino Unido. En ella, criticaba a ésta como institución acaparadora de funciones ejecutivas, legislativas y judiciales, haciendo obvio un modelo sin separación de poderes y más que necesitado de reforma. Erik Jürgens ${ }^{20}$, autor del documento, criticaba ese extraño diseño que hasta 2005 concitaba en manos de tal poderosa institución: funciones ejecutivas (cabinet minister) con importantes responsabilidades en el ministerio de justicia, un papel determinante en los nombramientos de la Judicatura en su totalidad (en especial, en la senior Judiciary); a su vez, funciones legislativas de primer rango (Lord Chancellor sería el Speaker de la Cámara de los Lores); y, por último, funciones propiamente judiciales al ser «Head of Judiciary» y Juez en activo ostentando el cargo de Presidente del Comité de apelaciones de la Cámara de los Lores (Appellate Committe of the House of Lords ${ }^{21}$ y del Judicial Committe of the Privy Council.

Ahora bien, tamaña reforma constitucional no se produjo de modo tranquilo y digno (en palabras del Le Seur ${ }^{22}$ ) sino que sorpresivamente fue poco a poco catapultada a la sociedad por filtraciones de la prensa. Se hacía el anuncio por el 10 de Downing Street el 12 de junio de 2003. Una decisión de reforma, tan decisiva

19 Este órgano es la máxima instancia jerárquica a la que pueden apelar los países de la Commonwealth, territorios dependientes de la Corona británica y otros territorios de ultramar sobre los que tiene jurisdicción el Reino Unido. Fue creado en 1833. https://www.jcpc.uk/

20 RESOLUTION 1342 (2003), Texto adoptado por el Comité permanente de la Asamblea parlamentaria del Consejo de Europa el 8 de septiembre de 2003 siendo su Rapporteur: Mr. Erik Jurgens. Ver también: ANDREw LE SEUR: «The Conception of the UK's Supreme Court», in Building the UK's Supreme Court, Oxford University Press, UK 2004; pp. 3-20;

21 Desde 2009 este extinguido órgano es ahora el Tribunal Supremo del Reino Unido.

22 «...It could have been a different, more dignified beginning for the new Supreme Court. Some of us regretted that so significant a constitutional reform had not been born of recommendations from a Royal Commission rather than a surprise press release and hastily written departmental consultation paper published shortly before Parliament's summer recess. 
para los años venideros, surgía de la forma menos ortodoxa posible en una vetusta democracia moderna: "policy making on the hoof» ${ }^{23}$.

No sólo el ejecutivo en sentido extenso se sintió al margen de tal anuncio de reforma, sino que la propia Judicatura manifestó su profundo enfado como la gran damnificada y la gran olvidada también ${ }^{24}$. Otros autores han interpretado el anuncio de la reforma constitucional, no tanto como algo improvisado a espaldas de la Judicatura sino, más bien, como una manera de sortear la férrea resistencia de la Senior Judiciary a ceder o, en cierto modo a perder, el enorme poder que disfrutaban antes de la reforma.

Y como siempre en todos los momentos complejos, el perfil de las personas al frente de las instituciones constituye un incentivo o un ingrediente disuasorio. En este caso, Lord Irvine (Lord Chancellor 1997-2003) y Lord Woolf (Lord Chief of Justice 2000-2005) supusieron unos largos años de laborismo (desde 1997 hasta 2010 con Blair y Brown como primeros ministros) y fueron personalidades decididas a favorecer tales reformas ${ }^{25}$.

Nuestra investigación se centra ahora en uno de los aspectos de la Constitutional Reform Act de 2005: el nuevo procedimiento de nombramiento de Jueces a través de un órgano independiente y no departamental del ejecutivo, de naturaleza pública y en estrecha colaboración con el Ministerio de Justicia, que tiene como función principal identificar/proponer candidatos a puestos de la Judicatura en todos sus niveles, pero que la práctica de más de diez años ha convertido en un verdadero órgano de nombramiento judicial. Hablamos de la Judicial Appointments Commission.

\section{EL VIEJO MODELO DE NOMBRAMIENTOS: «...TAP ON SCHOULDER AND SECRET SOUNDINGS»}

La independencia judicial resulta incontestable para disfrutar de una Judicatura legítima y confiable que garantice aquélla construyéndola día a día. El Act of Settlemen de 1701 derogó la facultad regia de nombrar Jueces a voluntad real, garantizando a principios del siglo XVIII, el disfrute y ejercicio del cargo de Juez del Rey mientras estuviera asegurado «Good behaviour». Asimismo establecía la compensación de aquellas funciones judiciales con unas remuneraciones a modo

23 Ahmed K., «Cabinet ignored over Historical Legal reforms», The Observer, 15 June 2003.

24 The Times, 2 August 2003: «...Lord Woolf, the Lord Chief Justice, is reported to have told Lord Falconer at the annual judges dinner, three weeks after the announcement that it must be a cause for concern than the decision to abolish a historic office (that the Lord Chancellor), with its pivotal role in the administration of justice as head of judiciary, can be taken without any consultation with the judiciary...»

25 M. Kate, G. Gee, R. Hazell, P. O'Brien, The Politics of Judicial Independence in the UK's Changing Constitution, Cambridge University Press, London 2015, pp. 162 y ss. 
de salarios. La política siempre ha estado presente en los procesos de selección de Jueces, la historia da buena cuenta de ello.

El modelo tradicional británico de nombramiento de jueces se había definido como: discreto, estable, económico y capaz de generar buenas relaciones entre el propio estamento judicial y el ejecutivo o Cabinet model. Un proceso desconocido e inespecífico, urdido de manera opaca afianzando, pacíficamente, una manera de proceder política y con profundas influencias de un estamento muy poderoso, la Senior Judiciary. ${ }^{26}$

Los pasos encaminados a los nombramientos se iban dando mediante pesquisas, consultas y conversaciones tranquilas que debían sonar «lo mínimo». Secret soundings ${ }^{27}$. Se llamaba en la puerta concreta cuando ya estaba todo urdido y decidido. Quién tuviera que enterarse y dar su consentimiento recibía esa simbólica palmada en el hombro (tap on shoulder) y el proceso poco más que habría llegado a su fin. Era evidente el peso decisivo de Lord Chancellor, una especie de «controlling hand...» en palabras de Woodhouse ${ }^{28}$. Una peculiar forma de proceder que podía incluso sorprender al candidato, ajeno a su potencial nombramiento hasta ese gráfico momento de la palmada en el hombro ${ }^{29}$.

Es evidente que con el esquema descrito, los candidatos elegidos y nombrados por Lord Chancellor serían hombres de confianza del ejecutivo y cómodos colaboradores de las políticas gubernativas. Al igual que, previamente, el nombramiento de aquél, también de naturaleza profundamente política, se producía entre hombres «de partido», con perfiles clásicos y en los puestos más altos de sus trayectorias político-profesionales. Señalaba Goldstream que el Primer Ministro, siempre seleccionaba para cubrir el puesto de Lord Chancellor a personas fiables, entendiendo por tal, de su partido político y de posiciones dentro de la Judicatura favorables al gobierno ${ }^{30}$.

El papel de los jueces en el Reino Unido ha cambiado, su poder ha crecido lo confirma la Human Rights Act 1998, una clara expansión del Judicial review

26 Woodhouse D., The Office of Lord Chancellor, Hart Publishing Oxford, London 2001, pp. 133 y ss.

27 A pesar de todo, es curioso leer en la academia inglesa y en los principales protagonistas de todo este profundo cambio en la judicatura que el anterior modelo, no era desde luego un foco ni de corrupción, ni tampoco un cheque en blanco para nombrar «malos jueces» o jueces tan sólo por ser cercanos o próximos a las posiciones del gobierno. Lord Irvine defendió, siendo Lord Chancellor que sus modos de proceder eran altamente profesionales y efectivos, teniendo muy presente la importancia de las muchas conversaciones, entrevistas y opiniones consultadas de otros jueces muy veteranos y autorizados. Y en una conferencia en 1997 dijo: «...to the sceptic I ask, what do you think happens at one of these consultation meeting? Do you honestly believe that my Permanent Secretary turns up at a senior judge's for asking whether of Copperfield is a good chap or whether young Pickwick is a bit suspect because, rumour has it, he voted for the Green Party at the last election. Nor, our consultations are not like that...», K. MALleson y R. Moules, The Legal System, Oxford 2011, pp.216.

28 Woodhouse D., The Office of Lord Chancellor, Hart Publishing, Oxford 2001, pp. 131 y ss.

29 Darbyshire P., Sitting in Judgment: the working lives of Judges, Hart Publishing, Oxford 2011, pp. 87 y ss. Ver también, Department of Constitutional Affairs, Constitutional Reform: a new way of Appointing Judges (CP 10/3 2003).

30 Goldstream G., «Judicial Appointment in England», n. ${ }^{\circ} 43$, Journal of the American Judicial Society', 1959, pp. 40 y ss. 
multiplicando y potenciando la tarea encomendada a la Judicatura inglesa. Sus relaciones con el legislativo han cambiado, y buena cuenta de ello es el nuevo Tribunal Supremo del Reino Unido, puesto que las funciones judiciales de la House of Lords como Tribunal superior de apelaciones desaparecen y se trasladan a aquél $^{31}$. Sus relaciones con la opinión pública ${ }^{32}$ navegan contra corriente y el episodio vivido tras el controvertido fallo del Tribunal Supremo Miller contra la Secretaria de Estado del Gobierno en el asunto del Brexit granjeó a los jueces titulares duros: "Judges enemies of the people...." ¿Y ${ }^{33}$ sus relaciones con el ejecutivo? A este poder se le arrebataron las competencias en materia de nombramientos ${ }^{34}$. Los comienzos fueron difíciles (como era previsible hostilidad frente a la pérdida de poder) pero la actualidad muestra un cambio de mentalidad rendido por la eficacia de los nuevos nombramientos.

Bell entiende que la independencia judicial es un mandato constitucional y, lamentablemente, sobre lo que no existe consenso es sobre su significado y exigencias $^{35}$. Todo ello dependerá de diversas variables, por ejemplo, la «cultura judicial prevalente» en un momento determinado. Los pasos hacia el profundo cambio se van dando. En 2012 desafiando a más de cuatrocientos años de historia, llegaba a ser por primera vez Lord Chancellor, Kenneth Clarke, un hombre que no era abogado, ni jurista, ni juez. Esto ponía de relieve que las costumbres e inercias de un modelo viejo se habían dinamitado.

31 «Judicial roles in the $21^{\text {st }}$ century are not now what they once were. The judicial work of the House of Lords at the creation of Great Britain in 1707 and the UK in 1801 was not allocated to a distinct and separate professional court. [...] The appellate work of the House of Lords was one part of the range of judicial and legislative responsibilities it possessed, and no sharp constitutional line was drawn between the judicial and the legislative function...» Goodall K., «Ideas of «Representation» in UK Court Structures» LE SEUR A., Building the UK'S new Supreme Court. National and Comparative perspectives, Oxford University Press 2007, pp. 69;

32 La Judicial Office en el sistema británico es una institución creada al albur de la Constitutional Reform Act de 2005, depende del Ministerio de Justicia y está provista de personal administrativo y funcionarios del Ministerio para dar apoyo y gestionar las relaciones de la Judicatura con la opinión pública a través de los medios de comunicación. https://www.gov.uk/government/organisations/judicial-office/about;

33 Andrew Le Seur señaló en 1996 que el importante crecimiento de las hostilidades y críticas desde el debate político y los medios de comunicación hacia los jueces debía ser entendido como parte de una estrategia más amplia para frenar desde el gobierno el desmedido y creciente poder del «judicial review»...» $\mathrm{P}$. O'BRIEN, «Enemies of the People»: Judges, the Media, and the Mythic Lord», Public Law, number extra about Brexit 2017, pp. 136 y 137;

34 Los procedimientos ante la JAC han dotado de estabilidad a las relaciones entre ésta y el Ministro de Justicia. Debe haber cooperación entre ambas instituciones, gran parte de los «nombramientos», que no propuestas o recomendaciones, siguen en manos del Ministro de Justicia (LC Lord Chancellor) pero, sorpresivamente para nuestros modelos occidentales, éste ratifica en un 99\% todas las recomendaciones que le llegan desde la JAC. Judicial Appointments Commission, Annual report and Accounts: 2006-7 (HC 632 2007); PATERSON Oве A., «Power and judicial appointment: squaring the impossible circle» Gee G., y Rackley E., Debating Judicial Appointments in an age of Diversity, Routledge 2018, chapter 3;

35 Bell J., "Judicial Cultures and Judicial Independence», European Legal Studies, n. 47 (60) 2001, Cambridge $\mathrm{Y}$. B. 


\section{NUEVO DISEÑO: LA JUDICIAL APPOINTMENT COMMISSION (JAC) DE 2006}

Los procesos de selección de los Jueces son, sin ningún paliativo, preocupación de primer orden en cualquier Estado del mundo.

Señalaba la Declaración de principios del año 2004 de la Commonwealth (Commonwealth Latimer principles) en materia de separación de poderes e independencia judicial (como referencia para los múltiples y diversos procedimientos de nombramiento de jueces) que: «...la Judicatura de cualquier país debe ser independiente, imparcial, honesta y competente [...] El objetivo de cualquier proceso de selección de jueces debe ser proveer con «herramientas fiables» al sistema, en el ánimo de identificar personas que posean las «cualidades» requeridas y tal búsqueda se haga de la manera legítimamente diseñada para garantizar y salvaguardar la plena «confianza pública» en la Judicatura». ${ }^{36}$

El Reino Unido, desde la CRA de 2005 ha depositado en manos de la Judicial Appointments Commission, los procesos de selección de Jueces. El cambio fue lento y difícil, tuvieron que darse ciertos pasos hasta llegar al modelo actual.

Varios antecedentes fueron relevantes en el proceso de cambio. a) La Commission for Judicial Appointments (CJA) de 2001; b) El ejemplo de Escocia y de Irlanda del Norte y el programa de reformas del Gobierno de Blair; c) El Concordato y las negociaciones que plantearon Lord Woolf y Lord Falconer que se publicaron en enero de 2004; y, d) La determinante posición del Consejo de Europa sobre el papel de Lord Chancellor, en cierta manera materializada por el informe de Erik Jürgen.

La falta de avances en «diversidad» fue clave en la creación de la Commission for Judicial Appointments (CJA) en 2001 Este órgano realizó un proceso de auditoría e investigación del viejo modelo judicial y sus conclusiones fueron severas. Se llegó a decir, que los secret soundings del viejo modelo eran un silenciador de una clara y enraizada tradición sexista. De manera endémica y crónica, la alta judicatura había dado la espalda a la diversidad $»^{37}$.

En el marco del proceso de Devolution, iniciado a principios del siglo xx en el Reino Unido y en materia de nombramientos judiciales, se crearon a través de la Justice Act 2002 varios órganos independientes de nombramientos, por un lado NIJAC (Northern Ireland Judicial Appointment Commission ${ }^{38}$ ) que vio la luz en junio de 2005 y, por otro, en Escocia la JABS (Judicial Appointment Board for Scotland ${ }^{39}$ )

36 The Appointment, Tenure and Removal of Judges under Commonwealth principles. A compendium an Analysis of Best Practice, British Institute of International and Comparative Law, 2015, pp. 15 y ss.

37 HC, Constitutional Affairs Committee, Judicial Appointments and a Supreme Court, (Court of Final Appeal): Evidence of Sir Colin Campbell, HC 1275i 2003); Department of Constitutional Affair, Constitutional reform: A New Way of Appointing Judges, CP 10/2003;

38 Judges Council for Northern Ireland, creado en 2010, compuesto por 11 miembros todos jueces sin competencias en materia de nombramientos. Solo representa a la Judicatura de Irlanda del Norte;

39 Judges Council for Scotland, creado en 2008 y compuesto por 16 miembros, todos jueces. Sus competencias son meramente de asesoramiento a la Judicatura. 
creado en 2002. Ambos de naturaleza institucional y territorial aportaron mayor legitimidad.

El Concordato ${ }^{40}$ fue el documento que recogió el resultado de seis meses de duras negociaciones entre Lord Chief Justice y LC (Lord Woolf y Lord Falconer) y en él se desarrollaron los contenidos de la reforma: los recursos económicos y de todo tipo con los que se contaría para implementarla, el nuevo papel y liderazgo de la Alta Judicatura, cómo se tramitarían las quejas o desacuerdos, las fases de los diversos nombramientos y un largo etc. Era necesario contar con una detallada hoja de ruta al margen de presiones políticas y dando luz verde a un nuevo procedimiento de nombramientos.

Y, por último, fue también relevante el informe Jürgens, ya mencionado, advirtiendo de la quiebra del principio clásico de separación de poderes y exigiendo la reforma de manera inminente ${ }^{41}$.

La Judicial Appointment Commission es un organismo independiente y público, que forma parte del poder ejecutivo, no está adscrito a ningún departamento, pero está financiado por el Ministerio de Justicia.

Comenzó a funcionar el 3 de abril de 2006 siendo su objetivo, desde el primer momento, hacer más transparentes, efectivos y eficientes los procedimientos para nombrar Jueces en el Reino Unido. Y ello, sin duda, significaba sustraer gran poder de manos de Lord Chancellor. La JAC está compuesta por quince miembros y su composición exige: 5 Jueces (1 de la Court of Appeal, 1 de la High Court, 1 a elegir entre Court of Appeal o High Court, 1 Circuit Judge y 1 District Judge), 2 Abogados en ejercicio (Practising lawyers), 5 Miembros laicos (lay members), 1 Miembro jurídico de algún Tribunal (legal tribunal member) y 1 Magistrado (lay Magistrate). ${ }^{42}$

El presidente de la JAC es un miembro no judicial, ni jurista (un perfil laico, de 2016 hasta 2019 ha ocupado el cargo un prestigioso Cirujano Lord Ajay Kakkar), diseña una estrategia política y un plan de trabajo con objetivos anuales en "política de nombramientos» negociando y debatiendo con el Ministro de Justicia. Este ingrediente de naturaleza estratégica-política resulta importante porque aporta enfoques ajenos y complementarios a las tradicionales visiones del poder judicial y ejecutivo, «aire fresco» en medio de vetustas y endogámicas aportaciones. En paralelo al Presidente está el Jefe del ejecutivo (Chief of executive) que lidera todo el personal administrativo y técnico dando soporte funcional a la JAC.

40 https://publications.parliament.uk/pa/ld200506/ldselect/ldconst/83/83.pdf;

41 «The Assembly very much welcomes the decision taken by the United Kingdom Government on 12 June 2003 - after the adoption on 28 April 2003 and subsequent publication of the report and draft resolution by the Legal Affairs Committee - to abolish, in the near future, the existing office of Lord Chancellor and to introduce legislation which will establish new institutions to discharge the functions currently discharged by the Lord Chancellor...», ibídem;

42 Schedule 12, Constitutional Reform Act de 2005; 
La JAC es un órgano de identificación-proposición de candidatos a las «autoridades de nombramiento» (decision-making authorities) que serán las que los nombren. Ahora bien, la estadística confirma que la JAC actúa como un órgano de puro nombramiento: desde 2006 hasta 2013, de las casi 3.500 recomendaciones de candidatos propuestas a la autoridad competente sólo no se tradujeron en cargos efectivos cinco.

Es imposible entender la naturaleza real de la JAC sin poner de relieve sus relaciones y cooperación permanente con el gobierno, concretamente con el Departamento de Asuntos constitucionales y de manera especial con el Ministro de Justicia. Las quince personas que integran la JAC desarrollan sus competencias a tiempo parcial compatibilizando su actividad con la propia de su carrera profesional de origen. Serán retribuidas por dietas o compensaciones parciales.

¿Quiénes son las autoridades de decisión a las que la JAC debe elevar su recomendación o propuesta y, finalmente, nombrarán a los Jueces?

El principio de jerarquía opera en la sistematización de tales recomendaciones y así: Senior President of the Tribunal (SPT) recibirá las sugerencias de candidatos para la mayoría de las posiciones a Tribunales, la Criminal Court Act 2013 (en adelante CCA), (Schedule 13, párrafo 30, expone algunas excepciones que siguen en manos de Lord Chancellor).

Para Courts inferiores a la High Court, las propuestas se harán a Lord Chief of Justice (LCJ) (CCA 2013, Schedule 13, párrafo 29) y, para los nombramientos a la High Court, será el mismo Lord Chancellor quién tenga que decidir sobre las recomendaciones de la JAC (CRA, sección 67-72 y 76-85). Además de tales recomendaciones el modelo sigue manteniendo claras competencias de nombramiento en manos de Lord Chancellor, sobre todo para puestos de gran relevancia (Senior Judiciary). Los miembros de la Corte de Apelación de la Cámara de los Lores (Court of Appeal), los Presidentes de las «divisions» que componen la High Court (Chancery, Family and Queen's bench divisions) y Lord Chief of Justice, son nombrados por procedimientos que dependen, en última instancia, de la decisión de Lord Chancellor.

¿Cómo se lleva a cabo el proceso para llegar a seleccionar y, por tanto, recomendar a un candidato?

Es importante diferenciar dos ámbitos de trabajo en la JAC: por un lado, el proceso ordinario de selección de candidatos en niveles judiciales hasta la High Court. Y, por otro, los procedimientos de selección de la denominada Senior Judiciary que incluye: Lord Chief Justice, Senior President of Tribunals, Heads of division y Jueces de la Court of Appeal. A estos dos procedimientos se suma la tarea desempeñada por la JAC en el nombramiento de los Jueces del Tribunal Supremo del Reino Unido creado en 2009. 
Los primeros niveles de posiciones judiciales ${ }^{43}$ hasta llegar a la High Court incluida se desarrollan bajo un mismo procedimiento.

La primera parte del procedimiento tras la reforma de 2005 se desarrolla a través de la publicación de la plaza vacante a cubrir que debe reflejar un perfil y descripción de esta lo más detallado y completo posible. Con la expresión Job description y la expresión Request for selection (section 87 y 88 CRA de 2005) el sistema combina, la publicidad de la convocatoria generando apertura a todos los potenciales candidatos y, al mismo tiempo, claridad en las exigencias y necesidades de esta. Todo ello en el ánimo de afinar al máximo qué tipo de perfiles y candidatos deben sentirse llamados.

Lord Chancellor debe consultar a Lord Chief Justice (LCJ) y en tales conversaciones y consultas deben fijarse: la completa descripción del puesto a cubrir y las posibles cualificaciones específicas, no reguladas y, por tanto, adicionales o complementarias que ambos pudieran acordar pensando en particulares necesidades. Es obvio, desde luego, que este espacio a decidir o «criterio adicional de selección» resulta incierto y un tanto problemático en las relaciones entre JAC, Ministro de Justicia y el departamento administrativo del Ministerio que se encarga de la gestión administrativa de las Courts y Tribunals (Inglaterra y Gales) ${ }^{44}$ denominado Her Majesty Courts and Tribunals Service (HMCTS). Es sin duda este espacio en blanco a cubrir donde se producen los enfrentamientos. El ingrediente discrecional y basado en razones heterogéneas, esto es, también de oportunidad por el momento y el perfil que se requiere en cada momento, se acepta y reconoce.

La JAC ha criticado el uso que ha dado a este adicional criterio de selección, el Ministro y HMCTS. Estos tradicionalmente han dado prioridad, por ejemplo,

43 La línea jerárquica natural del sistema del Reino Unido se desarrolla en línea ascendente: Tribunals, Magistrate's Court, Crown Court, County Court, High Court que comprende tres órdenes jurisdiccionales: Queen's bench Division QBD que se encarga de casos y asuntos civiles, reclamaciones de quiebras de contratos y reclamaciones por lesiones. Dentro de esta jurisdicción está también la Commercial court especializada en asuntos litigiosos de naturaleza comercial. Chancery Division, se encarga de asuntos relacionados con la quiebra de la ley de igualdad en materia de propiedad intelectual, sucesiones y testamentos, quiebras... Y Family Division que trata temas de todo tipo relacionados con el Derecho de Familia. Court of Appeal que se divide en jurisdicción civil y criminal y resuelve recursos contra la High Court, la County court y la Crown court. Tras la reforma de 2005 la Appellate Committee de la House of Lords ha sido sustituida por el Tribunal Supremo que conoce, como supremo órgano judicial de todos los asuntos de Derechos Humanos. Por último, está el Judicial Committee of the Privy Council, que conoce y resuelve recursos de apelación de sentencias de los países de la Commonwealth. Le Seur A., and Cornes R., The Future of the United Kingdom's Highest Courts, University College, London 2001; MALleson K., The Legal system, Oxford university press, London 2011;

44 HMCTS, Her Majesty Courts and Tribunal Service es un órgano del Ministerio de Justicia creado en 2011 fusionando el antiguo órgano de gestión de Cortes y por otro lado separadamente el órgano de gestión de los Tribunales en un único órgano que tiene como función principal la eficiencia y eficacia de los Tribunales y Cortes de Inglaterra y Gales en el Reino Unido, garantizando el acceso a la Justicia para todos. Este órgano tiene competencia sobre: Court of Appeal, High Court, Crown court, Magistrate's court, and County courts. Asimismo, será también responsable de la gestión administrativa y eficacia de funcionamiento en: las salas de los First-tier Tribunal o Tribunales de primera instancia y los Upper-Tribunal o Tribunales superiores, junto con los Tribunales laborales (employment Tribunals) y otros Tribunales especiales (inmigración o asuntos relacionados con el terrorismo). 
a que el candidato pueda desarrollar de manera inminente las funciones del puesto para el que ha sido convocado y que cuente en su formación y habilidades profesionales con la mejor de las preparaciones posibles, de esta forma no será necesario un proceso previo de formación o adecuación mediante cursos o prácticas en el Judicial College (órgano encargado de la formación práctica de Jueces). El efecto que ello ha producido, durante los primeros años de funcionamiento de la JAC, ha sido reducir los candidatos potenciales y minimizar la posibilidad real de «diversidad» en los mismos, optando siempre por perfiles muy cualificados y de un estrato social muy alto.

Poca diversidad y cierta decepción en los primeros años de actividad de la JAC que recibió como una herramienta completamente hostil a sus propósitos, los «criterios adicionales de selección de candidatos». A mayor imprecisión y ambigüedad en manos de la vieja guardia (Ministro y órganos del ministerio) más capacidad de seguir «repitiendo» los mismos perfiles, los mismos nombrados, una batalla lidiada para encontrar, a fin de cuentas, más de lo mismo...

A partir de los primeros años de vida de la JAC, el gran reto fue cómo sortear este obstáculo tan cómodo para el continuismo del viejo modelo y que sería, precisamente el elemento de la diversidad.

Cuando los candidatos ya se han postulado tiene lugar lo que ha dado en denominarse el desarrollo del «Selection day».

A modo de filtro inicial, los candidatos deben, una vez que se han postulado, superar un «test» de preguntas cualificadas diseñado expresamente (especificidades, conocimientos y habilidades requeridas), por expertos en la materia y compañeros en activo en plazas judiciales similares. Sobre los mejores candidatos que hayan superado el test y cuenten con perfiles adecuados al puesto en cuestión, la JAC elaborará una lista convocándolos a participar en la denominada jornada de «Selection day».

Esta jornada comprende una entrevista, una presentación por parte del candidato de su perfil y experiencia, una batería de preguntas con supuestos de hecho o casos posibles del puesto judicial a cubrir y, un supuesto de role-playing lo más acorde con el día a día del puesto a cubrir.

Enfrente del candidato y para conocer como órgano supervisor de todas las referidas pruebas del selection day, se halla un panel de tres miembros. Dos de ellos son miembros laicos y un tercero será un juez, preferiblemente del mismo ámbito y posición de la vacante. Los tres elaborarán un informe que será remitido a un miembro de la JAC (commissioner) seleccionado por el presidente de ésta para supervisar y dirigir todo el proceso pero sin tomar parte directa ni en la elaboración de la lista, ni en la jornada del Selection day.

Varios aspectos han sido criticados en estas primeras fases. Por un lado, la excesiva influencia o peso del panelista de origen judicial, a pesar de ser los otros dos miembros ajenos a la profesión. Y, por otro, la necesidad de recabar para los puestos de miembros laicos de las comisiones o paneles evaluadores perfiles variados y de niveles de formación adecuados y más altos de los que participaron en los primeros años de la JAC. 
Celebrado el encuentro con el panel y tras el referido informe del commissioner, se abre un proceso de «consultas»: Statutory consultation ${ }^{45}$.

El commissioner necesita contrastar información y consultar acerca de perfiles, experiencias y condiciones. La principal característica de esta consulta es que no es «vinculante» para el miembro de la JAC, pero si el candidato recomendado (por la JAC) no consigue una valoración positiva del sujeto consultado [(LCJ para vacantes en High Court, otro juez con experiencia apropiada y relevante en la vacante para nombramientos low level Courts y para nombramientos de tribunales SPT (Senior President Tribunals)], tal discrepancia deberá ser fundamentada por la JAC en su informe (CRA, section 89).

La realidad de los hechos pone de relieve que en los nombramientos de los niveles medios y bajos de la judicatura no se producen discrepancias y sí, en cambio, surgen algunas a medida que los puestos a cubrir pertenecen a la senior judiciary. Y es cierto, además de evidente, que el nombramiento no se produce por la autoridad competente, si el candidato recomendado por la JAC no coincide con la valoración positiva y conforme de la autoridad (Senior judiciary) consultada previamente. Una especie de veto encubierto que granjea la última palabra, de nuevo, a los principales actores del viejo modelo.

De hecho, doctrina y miembros de la JAC han valorado de muy distintas maneras qué sentido y consecuencias se desprenden de las obligatorias consultas que deben hacerse antes de la propuesta de recomendación. Algunos plantean que son: «excesivas influencias», «intentos de manipulación» y otros, interpretan aquellas consultas como una «información distinta y complementaria», difícil de conseguir con los procedimientos reglados y formalistas pero que deviene utilísima por cuanto es capaz de evitar candidatos no apropiados, a la larga, para puestos importantes ${ }^{46}$.

El momento de la verdad llega con la recomendación formal del candidato por la JAC a la autoridad de nombramiento. El mérito, el buen carácter y una clara apuesta, (de entre los candidatos posibles y en igualdad de méritos), por la diversidad serán los tres parámetros a considerar.

45 Es muy importante reflexionar sobre la «naturaleza» de la consulta, tan inserta en el «ADN» británico. La consulta o «statutory consultation» es un trámite obligatorio pero sin carácter vinculante para la decisión final. No obstante si hay divergencias entre quien consulta y el consultado, el nombramiento no se produce. Esta práctica consolidada en la judicatura británica resulta un activo y no se ha abandonado tras la reforma de 2005. «... One of the mysteries of all this is that government departments still consult the judges as they draft legislation. For instance, Lord Woolf s Cambridge speech reveals that the judges were consulted by the Home Office as they drafted the Immigration Act. The problem for the judges was that the Home Office then ignored their advice...» Woolf H., «Judicial Review, The tensions between the executive and the Judiciary», Law Quarterly Review, 114, 1998, pp. 579.

46 «...Today, there is said to be a shared understanding between the JAC, the senior judges and the Ministry that statutory consultation is an opportunity for a judicial consultee to provide information that is not likely to have been disclosed in the selection process, including information of the skeleton-in-the-cupboard variety that might make individuals unsuitable for judicial office.» in GEe G., MALLESON K., HAZELL R., and O'BRIEN P., op. cit. pp. 175 y ss. 
El volumen y necesaria agilidad de las recomendaciones en aras de crear un procedimiento efectivo y eficiente hace que en los dos encuentros al mes, aproximadamente, que mantiene la JAC se lleven a cabo alrededor de 75 recomendaciones, pero no todos los puestos deben ser objeto de comentarios o especial reflexiones, lo normal es asumir los informes de los miembros de la JAC que a su vez dan por válidos las evaluaciones de los paneles. Y es para los casos que plantean alguna discrepancia o complicación, para los que la JAC dedica cierta parte y discusiones en sus reuniones.

Una vez que la recomendación ha sido hecha, la autoridad de nombramiento puede aceptarla, rechazarla o solicitar su reconsideración. Según la CRA de 2005 solo cabe el rechazo, si se entiende que el candidato es inapropiado para el puesto, y la reconsideración, cuando no hay suficientes «evidencias» de que el candidato recomendado sea el mejor posicionado de acuerdo a la ponderación y valoración de los méritos.

Todas las posibles autoridades de nombramientos: Lord Chief Justice (LCJ), Lord Chancellor (LC) o Senior President of Tribunals (SPT) deben «motivar» su rechazo o su decisión de reconsideración. En la práctica casi no se han producido.

Cuando los puestos a cubrir son de órganos judiciales superiores a la High Court, esto es, Senior Judiciary ${ }^{47}$ (LCJ, SPT, Heads of division y jueces de la Court of Appeal) se articula un procedimiento separado ${ }^{48}$. Las resistencias a la pérdida de poder e influencia por parte del ejecutivo en los nombramientos judiciales más relevantes y de mayor poder, son una evidencia.

Como para el resto de las vacantes, el punto de salida es también el esfuerzo de «descripción» de las habilidades y necesidades demandadas. Tarea que no siempre reflejaría consenso y sintonía de los perfiles judiciales consultados. Los jueces senior consultados por LC, solían coincidir en sus visiones conservadoras y clásicas de las necesidades y perfiles del puesto a cubrir, pero los cambios introducidos con motivo de la CRA 2005 y su reforma en 2013 lograron introducir variables significativas en los «Job descriptions» tan relevantes como la que directamente señalaba LCJ en $2013^{49}$ haciéndose hincapié en la capacidad de liderazgo y compromiso con la modernización de la justicia, la búsqueda incesante de eficiencia y eficacia y el firme compromiso con la diversidad.

Se crea en cambio, para este tipo de nombramientos, un órgano ad hoc que hasta 2013 estaba compuesto por cuatro miembros y desde entonces se compone

47 CRA, section 67-84, reformadas por la CCA de 2013;

48 La composición de la comisión ad hoc que se creará para el nombramiento de cada vacante, dentro de la Senior Judiciary, a cubrir está regulada con ciertas especificidades, Judicial Appointments Regulations 2013, regs. $5,11,17$ y 23 ;

49 El discurso de Lord Chief Justice, señala la necesidad de «rediseñar la Justicia» a la luz de las necesidades de los nuevos tiempos. https://www.judiciary.uk/wp-content/uploads/JCO/Documents/Speeches/ lcj-speech-reshaping-justice.pdf Lord Thomas of Cwngied, 2017 
de cinco miembros, (dos elegidos por Lord Chief Justice). Preside LCJ quien tiene voto de calidad en caso necesario y además forma parte un juez senior, el presidente de la JAC, que es un miembro laico, y otro miembro de la JAC. Con la modificación a cinco miembros, el quinto será otro juez senior pero siempre manteniéndose una mayoría laica. Una de las notas propias de este procedimiento especial de la JAC es su gran opacidad y su escaso o casi inexistente formalismo. Si bien, desde 2011 aproximadamente, las cosas han ido cambiando y se ha introducido poco a poco un mayor nivel de transparencia y formalización, en parte, fruto del «empecinamiento» de la realidad (el efecto producido por los procesos ordinarios de la JAC creando una cultura de nombramientos más delimitada, formal, estable y rigurosa es imparable).$^{50}$

El proceso ahora es más reglado, a pesar de su gran libertad de actuación. Las deliberaciones de los miembros del panel son secretas y ello es un gran óbice para poder valorar el peso que juegan jueces seniors y miembros laicos en las negociaciones.

Asimismo, el papel jugado por Lord Chancellor ha continuado muy activo como gran consultado para todas las plazas «senior».

En definitiva y respecto de las posiciones judiciales más relevantes o senior, los procedimientos siguen conservando «mucho» del viejo modelo reflejando serios déficits de legitimidad y diversidad. Figuras muy relevantes de la sociedad inglesa como Lady Hale, presidenta del Tribunal Supremo del Reino Unido al escribir estas líneas, han dicho que los nombramientos de la Senior judiciary son, en sentido amplio, un conjunto de actos políticos ${ }^{51}$.

El nuevo modelo de nombramientos es un cambio sin duda en fondo y en forma.

Órganos distintos para nombrar y para recomendar candidatos

Los miembros de la JAC desarrollan una labor de filtro «en tiempo real»y esto es importante respecto de los potenciales candidatos a ocupar el puesto. La JAC tiene como principales objetivos a cubrir: seleccionar candidatos con procedimientos basados sólo en el «mérito», recomendar candidatos que tengan «buen carácter» y orientar sus procedimientos de selección y análisis de los candidatos

50 «...So the much-criticised «tap-on-the shoulder» method of recruitment — which the JAC was set up to replace - has been discreetly reinstated. What's different is that it's senior judges who are doing the tapping rather than the Lord Chancellor — and it's now much more like a shove in the back. We can expect to see a number of lawyers who've either spurned a judicial appointment or been spurned by a misconceived appointments system sitting part-time in the coming months and being fast-tracked into the high court...», Rosenberg, J., «Senior judges are hanging up their wigs. Replacing them won't be cheap» The Guardian, 4 Abril 2016;

51 Paterson A. y Paterson C., «Guarding the Guardians? Towards an Independent, Accountable and Diverse Senior Judiciary», London: Centre-Forum, 2012, pp. 36 y ss. 
desde un firme compromiso con la «diversidad». No estamos ante un proceso que analiza un currículo cerrado y unos méritos documentados que se exponen y defienden, los procesos de la JAC combinan estrategias activas que pretenden evaluar los candidatos en tiempo real con toda una serie de pruebas y actividades enfocadas a ello (short listing, selection day, role play...)

La diversidad ha sido siempre la asignatura pendiente en el proceso de selección de jueces en el Reino Unido, no sólo por su desprecio durante muchos años de historia británica de nombramientos judiciales, sino por su deficiente comprensión e implementación por sucesivos años de laborismo y gobiernos torys. Los denominados BAME (Black people, Asian and Minority ethnics) o colectivos minoritarios de la sociedad británica han estado y siguen relegados a planos muy secundarios del mundo judicial. Y así, por ejemplo, hasta 2004 no llega a la High Court ninguna jueza mujer y de color. Será Linda Dobbs quien lo haga por primera vez. La diversidad significa a medio y largo plazo una nueva visión y aires frescos en la aplicación de las normas, en esa búsqueda incesante de la «justicia». No siempre hombres, no siempre blancos, no siempre modelo de educación «Oxbridge», no siempre «Barrister», como perfiles más cotizados.

La «legitimidad» de la justicia requiere no sólo de buenos procedimientos para nombrar los jueces, sino un claro compromiso con la renovación de quiénes podrían ser los mejores candidatos para esos puestos. La independencia judicial requiere también de amplitud de perfiles y sensibilidades reflejando la verdadera heterogeneidad de la sociedad, última destinataria de los fallos judiciales.

\section{Participar activamente en el diseño y límites de la relación: política-nombramientos}

La claridad, visibilidad y tangibilidad de relación entre el elemento «político» y los procedimientos desarrollados por la JAC. El modelo actual de selección de jueces en el Reino Unido, es consciente del profundo peso que tiene la «política» en los procesos de nombramientos de jueces. Esto no es nuevo y seguramente tampoco es exclusivo de este modelo institucional democrático contemporáneo. Nombrar a los titulares del poder judicial es elegir a quienes deben asumir los poderes y responsabilidades de la iuris dictio. El peso de la ley en el Estado de Derecho se administra por los que ya en las revoluciones liberales burguesas fueron «boca de la ley».

Pero ser consciente de tal presencia, empecinada y persistente presencia, de la política en los procesos de nombramientos de jueces, no es más que un primer paso y como tal no es suficiente.

¿Cómo y hasta cuánto permitir que la lógica política y sus objetivos inunden los procesos de selección de la judicatura? Esconder la interacción de una y otros, puede ser una actitud (por desgracia muy frecuente), máxime cuando aquélla pretende sin límites, dominar éstos. 
Reglamentarla de manera clara, sencilla y transparente puede ser otra actitud. La idea que nos propone el nuevo modelo de la JAC adopta como actitud, la visibilidad, claridad y tangibilidad de los efectos de la política en los procesos de nombramientos de Jueces.

Visibilidad, porque las normas que regulan la composición y funciones de la JAC (CRA de 2005 y CCA de 2013 y JAC Regulations 2013) describen un procedimiento claro de recomendaciones, por un lado, y autoridades de nombramiento judicial, por otro. Autoridades que son parte activa de la política (Ministry of Justice) y estrecha colaboración con el Departamento de Asuntos constitucionales, dentro del ejecutivo (Department for constitutional Affairs DCA). En realidad, la mayoría del personal al servicio de los commissioners, trabaja apoyado y en cooperación con el DCA.

Claridad, en cuanto que Lord Chancellor será responsable (accountable) ante el Parlamento, del desarrollo y de las actividades que son desempeñadas por la JAC. Los objetivos y retos que asumirá la JAC en su periodo anual de ejercicio, así como las directrices de su Staff, de sus commissioners, su Presidente y Jefe ejecutivo (Chair y Chief of executive) son aprobados por Lord Chancellor. Claridad también puesta de relieve en el envío de los puestos vacantes a cubrir, (su localización y las exigencias, requerimientos o perfiles oportunos de tales plazas, especificados al máximo) en el ánimo de presentar a Lord Chancellor un único nombre. Así se limita in extenso el derecho de «rechazo» o «solicitud de nueva reconsideración» de Lord Chancellor sobre el candidato propuesto. Un clarísimo ejemplo de nuevo diseño en la relación política-nombramientos judiciales.

Tangibilidad de los efectos de la política sobre los procesos de recomendación-nombramiento tal como se desprende de la «jerarquización» de las autoridades de nombramiento y de los puestos o vacantes judiciales a cubrir. No será igual nombrar a un Juez de la High Court, que a un Magistrado de distrito. Y por eso, tal como hemos descrito el proceso de los reportes de las recomendaciones, dependiendo del puesto a cubrir, será destinado a autoridades de nombramiento distintas. Proximidad clara y palpable de la fuerza de lo «político» y «la política», en los casos de rechazo o petición de reconsideración, que consiguen finalmente evitar el nombramiento.

Es necesario medir, en el sentido de limitar pautadamente y controladamente, la presencia de la política en los nombramientos judiciales, vendría a ser, tanto por la forma como por el fondo, el equivalente a una «voladura controlada». Esta es a nuestro juicio la clave: participar activamente en el diseño y límites de la relación política-nombramientos.

\section{Combinar de manera positiva la heterogeneidad de perfiles de los miembros de la JAC}

Se trata de concitar, equilibradamente, Jueces, juristas y personas de fuera del mundo judicial. Se establece, prescriptivamente, que la presidencia de la JAC debe ser ejercitada por un perfil laico en derecho y al mismo tiempo se reconoce 
la importancia de la presencia de un «juez» en los paneles de selección, subrayando la no reemplazable tarea que debe desarrollar éste.

La representación de la pluralidad social, los necesarios distintos perfiles, la insustituible formación profesional técnica, la experiencia y «veteranía» o madurez de los Jueces senior, son imprescindibles. ${ }^{52}$ Pero también el «aire fresco» que representan los perfiles laicos.

\section{El efecto del «rechazo» o sugerencia de «nueva reconsideración» por parte de Lord Chancellor}

Cuando la recomendación que hace la JAC llega al Ministro de Justicia en los procesos normales sustanciados ante aquella, se pueden producir tres opciones. Primero, que se acepte la recomendación y se proceda al nombramiento poniendo este a disposición de su Majestad la Reina; segundo, que se rechace el candidato recomendado y, tercero, que se solicite a la JAC una «reconsideración» del candidato en concreto.

Estos dos últimos supuestos se originan, bien porque se entiende que no son los más apropiados para el puesto o vacante a cubrir, bien porque se considera que no hay suficientes evidencias que avalen al candidato para el puesto. Todo ello se aclara ante la JAC y se le pide que lo razone o justifique de manera escrita. La JAC puede, por tanto, plantear un nuevo candidato (en caso de rechazo del primero) o en caso de reconsideración, plantear otra vez el mismo, dotándole de más evidencias que lo apoyen o intentar de nuevo el candidato primeramente propuesto. También aquí LC cuenta con las mismas opciones de rechazo/reconsideración por lo que podría darse una tercera ronda de recomendaciones e intervención de la JAC e incluso un tercer y nuevo candidato propuesto. Pero tras esta hipotética tercera ronda, LC tendría que, bien aceptar alguno de los «no rechazados» anteriormente o, el propuesto en la tercera ronda.

La práctica pone de manifiesto, que la mayoría de los casos son de aceptación de la recomendación elevada por la JAC ${ }^{53}$. Y, no debe olvidarse, que todo este

52 G. GEE, Judging the JAC. How much judicial influence over judicial appointments is too much?, Debating Judicial Appointment Commission, Routledge 2018, capítulo 8;

53 https://publications.parliament.uk/pa/ld201012/ldselect/ldconst/272/27205.htm\#note36; En 2010, LC aprobó 686 nombramientos judiciales, 400 para posiciones en Tribunales, 284 para puestos en Cortes y dos para el Tribunal Supremo. Es decir, se aceptaron todas las recomendaciones de la JAC excepto una que fue sometida a «reconsideración» pero acabó finalmente prosperando. (Sir Nicholas Wall como candidato a cubrir el puesto de presidente de la «family division» de la High Court), ver GeE G., Malleson K., Hazell R. y O’brien P., op. Cit. Pp. 185 y 186; En 2010 siendo LC Jack Straw este exigió a la JAC que reconsiderara el nombramiento del candidato para el puesto de Presidente de la Family division de la High Court, Sir Nicholas Wale. El momento resultó decisivo, se abordaba una de las más esperadas y complejas reformas de esta jurisdicción y Straw consideraba que las duras y críticas declaraciones de Wale a las políticas del gobierno, sobre todo en materia económica, le hacían poco apropiado para el cargo. Un proceso electoral inminente, la prensa acechante y la urgencia de cubrir una muy relevante vacante hicieron que su inicial solicitud de reconsideración acabara por nombrar al candidato. 
proceso se complementa con las pertinentes consultas que llevará a cabo LC con la Senior Judiciary respecto de los candidatos recomendados en cuestión.

Es evidente que el poder de «rechazo/reconsideración» en manos de LC como algo simbólico y de difícil éxito, en términos de apartarse de modo definitivo de la recomendación de la JAC, pone de relieve burdamente cómo el peso real y efectivo del Ministro de Justicia en los nombramientos se ha visto recortado. A cambio, los hechos vividos con el caso de 2010 dieron como resultado que LC debería ser consultado en todo proceso de nombramientos de la alta judicatura, al comienzo del proceso, esto es, antes de que se reuniera el panel de selección. Por lo que, el denominado veto de LC (al final del proceso), se convertía en una herramienta de difícil uso, de rara eficacia y muy vigilada por los medios y agentes político sociales. Convenía entonces buscar otro momento de influencia y, efectivamente, así se hizo. Se reguló como obligatoria su consulta de manera previa, esto es, anterior al diagnóstico de requerimientos adicionales para el puesto a cubrir.

Excesivos costes burocráticos y, en definitiva, económicos en el desarrollo de los procesos

La práctica iba poniendo de relieve que los procesos eran demasiado largos y que a pesar del incremento de presupuesto, se requería mucho personal gestionándolos. Los primeros años de vida de la JAC llevaron a todos los sectores implicados a criticar la excesiva «burocratización» de un procedimiento lento y complejo ${ }^{54}$. Si bien es cierto que la situación ahora ha mejorado, suavizándose las relaciones entre el gobierno, y los sectores más críticos de la Judicatura. Los costes reales se han reducido en términos absolutos.

\section{LA PARTICIPACIÓN DE LA JAC EN LOS NOMBRAMIENTOS DE LOS JUECES AL TRIBUNAL SUPREMO DEL REINO UNIDO}

El artículo 23 de la Constitutional Reform Act de 2005 reconoce, regula y garantiza, como el máximo órgano judicial del Reino Unido, a su nuevo Tribunal Supremo. Pero no será hasta 2009 cuando este nuevo órgano sustituya de manera definitiva al extinto Appellate committe of the House of Lords.

Surge como pilar definitivo de la unwritten constitución británica para resolver asuntos de la más alta relevancia pública y constitucional. Compuesto por 12 jueces (Law Lords, ahora Justices of the Supreme Court) y disfrutando de la máxima jerarquía en el poder judicial, conoce en última instancia de asuntos civiles con jurisdicción en Inglaterra, Gales, Norte de Irlanda y Escocia y, en asuntos penales

54 G. Gee y E. Rackley, op. cít., Capítulo 1: «Introduction. Diversity and the JAC's first ten years», pp. 21 y ss. 
también, a excepción de Escocia. La cualificación legal que exige la CRA de 2005 para poder ser nombrado Juez del Tribunal Supremo será de dos años como Juez en alguna High Judicial office o al menos quince años de ejercicio de la abogacía profesional (section 25, CRA)

El origen de este nuevo Tribunal estribaba en la necesidad y urgencia de separación de poderes entre legislativo y judicial. Tanto es así, que dicha separación se consagraría también con un edificio alternativo a la propia Cámara de los Lores en el Palacio de Westminster. Hoy la sede del Tribunal Supremo es el Palacio de Middlesex Guildhall.

¿Qué modelo debía encarnar el nuevo Tribunal Supremo? Esta cuestión estuvo flotando de manera persistente en sus orígenes, aún hoy sigue sin despejarse. ¿Debía nacer a imagen del Tribunal Supremo de los EEUU, con poder para derogar leyes aprobadas por el Parlamento británico contradictorias con la Human Rights Act de 1998, superando el escalón (considerado por algunos insuficiente) de una mera declaración de «incompatibilidad»?

O, por el contrario, ¿debía nacer al calor de las Cortes constitucionales europeas, surgidas para ejercer el monopolio sobre asuntos constitucionales de relevancia? La respuesta a este complejo asunto no fue, ni es fácil. La doctrina británica, para constatar tamaña dificultad percibía, que si bien los objetivos iniciales fueron unos, los desarrollos posteriores están siendo otros. Si bien la primera y más fuerte inspiración fue crear un Tribunal a imagen y semejanza del Tribunal de Justicia de la Unión Europea, sus derivas y fallos se iban aproximando, con matices, a un Tribunal Constitucional propio de un modelo de constitucionalidad concentrado. ${ }^{55}$ Pero esta difícil cuestión excede a este trabajo que pretende centrarse en los procesos que la CRA articuló para nombrar a sus 12 jueces.

Lady Hale, se pregunta si sólo hombres, sólo blancos y sólo de origen británico son representativos de la sociedad real de este país ${ }^{56}$. ¿Tal vez estén representando a otro planeta?

El procedimiento de selección de los Jueces del Tribunal Supremo es único y especial respecto de los vistos en párrafos anteriores. Este mecanismo se pone en marcha cuando se origina una vacante en el Tribunal Supremo de alguno de sus 12 miembros. (Part 3, Shedule 23-60). Serán mantenidos en el cargo, bajo la vieja fórmula good behaviour hasta la edad de jubilación, pero podrían ser retirados si ambas cámaras legislativas así lo decidieran. Supuesto este poco probable que

55 LE SEur A., Building the UK'S new Supreme Court. National and Comparative perspectives, Oxford University press, 2007, pp. 6 y ss. LORD Hope, «A Phoenix from the Ashes? Accommodating a New Supreme Court», Law Quarterly Review, vol. 121, 2005, pp. 250 y ss. MASTerman R., Murkens J., «Skirting supremacy and subordination: the constitutional authority of the UK Supreme Court», Public Law, vol. 4, October 2013, pp. 800 y ss;

56 The Guardian, 1st June 2019, https://www.theguardian.com/law/2019/jan/01/lady-hale-supremecourt-president-judges-diversity 
no se produce desde $1830^{57}$. La edad máxima de un Juez en el Tribunal será de 70 años, teniendo entonces que retirarse de manera obligatoria, tema que ha sido muy controvertido máxime con la referencia al modelo americano que sigue consagrando a sus jueces en el cargo hasta el final de sus días.

Para nombrar a los jueces del Tribunal Supremo, se crea una comisión ad boc compuesta de cinco miembros que está integrada por el Presidente de la JAC, el Vicepresidente y, otros tres miembros que representan, como commissioners, a los cuerpos públicos de nombramientos territoriales de Escocia e Irlanda del Norte, respectivamente: JABS (Judicial Appointment Board for Scotland 2002) y NIJAC (Northern Ireland Judicial Appointment Commission 2005). Es curioso que la CRA de 2005 tan sólo establezca que de estas tres últimas personas al menos una debe ser laica, pero en cambio no prefija la ponderación de representación territorial de los referidos órganos en cuanto a mayor presencia de Escocia o de Irlanda del norte.

La influencia judicial en la comisión es un hecho y, si bien es cierto que el role jugado por Lord Chancellor ha quedado reducido a rechazar o solicitar una nueva reconsideración del candidato, no lo es menos que, la comisión no estaría dispuesta a insistir en un nombramiento que no cuenta con la confianza del gobierno. A ello hay que añadir la consulta que suele trasladar la comisión, por prescripción normativa a Lord Chancellor, y a los primeros ministros de Escocia y Norte de Irlanda, a sus Secretarios de Estado y, por otro lado, a los jueces en activo del Tribunal Supremo. Once opiniones de la máxima relevancia, por cuanto conocedores de primera mano de la realidad y problemas de este órgano y que serían muy difícilmente rebatibles por el resto de los miembros de la comisión.

$\mathrm{Y}$, ¿quién guarda al guardián? ¿Cómo se nombran o seleccionan los commissioners que integran la JAC? Será clave reflexionar sobre ello. El modelo inglés responde con una peculiar máxima, no demasiado familiar para culturas occidentales ancladas en modelos jurídicos civil law. El éxito descansa en: «no poner todos los huevos en la misma canasta...»

Esto es el sencillo y a la vez complejo modelo británico. Expertos y académicos coinciden en su gran complejidad a la hora de seleccionar a sus 15 miembros (Statutory Instrument n. ${ }^{\circ}$ 2191, Judicial Appointments Commission Regulations de 2013.) La regulación de la composición de este órgano se fijó en la CRA de 2005 y en una ley posterior de modificación de la misma, Crime and Court Act de 2013 desarrollada por el instrumento normativo referido.

El Presidente de la JAC cargo unipersonal es nombrado por la JAC pero debe contar con la aprobación de Lord Chancellor, lo cual no resulta en ningún caso baladí. ${ }^{58}$ La selección de los miembros de la JAC se hace mediante un proceso abierto competitivo (concurso de méritos en combinación con otras pruebas que

57 Existe un procedimiento interno habilitado para tramitar las posibles quejas o reclamaciones que pudieran surgir frente a los jueces del Tribunal Supremo. Judicial Complains procedure, que en sus artículos 1 a 3 ;

58 Constitutional Reform Act 2005, Sch. 12, párrafo 22; 
forman parte del proceso para postularse al puesto) ante el Ministerio de Justicia, de manera expresa ante Lord Chancellor (Ministry) a excepción de tres de los miembros con perfil judicial (los senior de entre los siete) que serán nombrados por el Consejo de los Jueces (Judges' Council) ${ }^{59}$.

Se crean paneles de cuatro expertos que serán elegidos por Lord Chancellor, Lord Chief of Justice y Senior President of the Tribunal respetando una gran heterogeneidad de composición en cuanto a perfiles y especialidades (regulations 13 y 14 Statutory Instrument 2013, n. ${ }^{\circ} 2191$ ) y que elegirán todos los demás miembros de la JAC que no caen bajo la elección directa del Consejo Judicial.

El mandato de los miembros de la JAC es limitado, en principio, el mandato será renovable por periodos de dos o tres años o incluso cabe, como máximo, un mandato de hasta cinco años renovable por otros cinco, pero siempre con un límite de 10 años máximo. El órgano destaca por la diversificación de un procedimiento profundamente burocrático (varios miembros, varias fases), la gran heterogeneidad de sus perfiles y miembros, la ausencia de votaciones como mecanismo clásico de decisión, el diálogo y negociación como criterios de decisión.

Y, en último lugar, podríamos añadir, la bolgura y ambigïedad de una disposición normativa que para un jurista continental formado en las corrientes de civil law, resulta desde luego chocante y más proclive a sospechas y prejuicios. Habrá por tanto que bucear de manera inversa en la «efectividad», legitimidad y calidad de los nombramientos.

Shetreet y Turenne dicen que hablar de nombramientos judiciales y de los procesos que les sirven de instrumento es hablar de integridad e independencia judicial. Si aquellos son buenos jueces, será en gran parte, porque éstos (los procesos) han sido adecuadamente diseñados. Y solo un Poder Judicial será justo, equilibrado, independiente y eficiente si tiene «buenos» jueces ${ }^{60}$. Hans Kelsen en 1926 señalaba que los Jueces nunca pueden simplemente limitarse a enunciar una ley o hacerse eco de la voluntad de un legislador, los jueces en sus decisiones eligen entre valores que se hallan en conflicto ${ }^{61}$.

¿Qué procedimiento para nombrar jueces es el mejor? Difícil respuesta si es que existe, desde luego. Lord Clarke señalaba que un procedimiento de selección y nombramiento de Jueces debe ser: abierto, basado en el «mérito», en la garantía del «buen carácter» de los nombrados y comprometido con la «diversidad». ${ }^{62}$

59 Este órgano, el Judges' Council se reguló normativamente por primera vez en la Judicature Act 1873, fue presidido por Lord Chancellor y todos los jueces del Tribunal Supremo son miembros. En la actualidad y tras las importantes reformas sufridas en 2002 y con la CRA de 2005 es presidido por Lord Chief Justice y sus miembros provienen de todos los ámbitos de la judicatura, incluidos Jueces de circuito y de distrito, magistrados y tribunales.

60 Shetreet S. y Turenne S., Judges on trial. The independence and accountability of the English Judiciary, Cambridge University Press, United Kingdom 2013, pp. 102-103;

61 Kelsen, H., The General Theory of Law and the State, Russell \& Russell 1961, pp. 153 y 154;

62 Clarke, L., «Selecting Judges: Merit, Moral courage, Judgment and Diversity», High Court Quarterly Review 49, 2009, (5); 
1. Los criterios de selección de los jueces deben ser públicos, claros y fácilmente comprensibles por todo tipo de ciudadanos. Para ello, ese conjunto de normas o criterios articulando el proceso deben poder ser criticados, cambiados con cierta flexibilidad y de fácil seguimiento e investigación.

2. Los responsables de los procedimientos de selección deben ser públicamente conocidos, en cada paso, en cada trámite, en cada informe, etc... Para conseguir tal objetivo las opciones son variadas, por ejemplo: los currículos de los miembros de los paneles o de la JAC, de las autoridades de nombramiento, de los sujetos consultados deben ser públicos; la posible o potencial opción de mecanismos de accountability ante el Parlamento o el ejecutivo respecto del papel desempeñado por estos, también sería de gran ayuda. En el Senado de Estados Unidos se aprueba y debate, por ejemplo, el candidato a ser juez del Tribunal Supremo de los EEUU; la JAC elabora anualmente un informe dirigido a Lord Chancellor detallando todos los procesos de recomendación de jueces celebrados durante el año y las quejas que sobre los mismos hubieran podido tener lugar. Quejas que se sustancian ante un órgano llamado JACO (Judicial Appointments Commission Ombudsman); también LC debe emitir un informe escrito razonado sobre los casos de veto o reconsideración de un candidato recomendado, o incluso, rechazado. Y, por último, las personas responsables de la selección/recomendación deberían ser independientes del ejecutivo y del legislativo, de ahí que sea muy importante cómo se selecciona a los commissioners y a las autoridades de nombramiento.

3. La «apertura» de los procesos para ser elegido miembro de la JAC es también decisiva. El perfil de los commissioners debe ser amplio, plural y representativo de la sociedad real. Esto otorgará importantes dosis de legitimidad a un órgano con tan relevantes competencias. Sólo así la sociedad se sentirá verdaderamente representada, sólo así se estará construyendo confianza legítima en la Judicatura como institución que presta un servicio público.

4. Un sistema de selección debe fundamentarse en el «mérito» y este concepto ambiguo y amplio ha ido mutando con los tiempos. Ello es bueno y malo al mismo tiempo. Antes de la reforma de la CRA de 2005 los criterios que definían el mérito se fijaban reglamentariamente por el Gobierno y así existe un documento de 2003 del Ministerio de Justicia especificando cuáles serían tales parámetros para ponderar el mérito de un determinado candidato ${ }^{63}$. Tales criterios se han ido completando y modificando con el nuevo procedimiento ante la JAC.

MORISON explica que el concepto de mérito no es algo estático, sino que como fiel reflejo de la sociedad debe ser un concepto dinámico que implemente y

63 http://www.dca.gov.uk/consult/jacommission/\#3; Tales criterios son: a)conocimientos legales y experiencia, b)habilidades intelectuales y analíticas, c)capacidad de juicios, d)decisión, e)capacidad para comunicarse y escuchar, f)integridad e independencia, g)justicia e imparcialidad, h)adecuada comprensión de la gente y de la sociedad, i)madurez y temperamento, j)cortesía, k)compromiso, conciencia y diligencia. Otro factor de gran relevancia y consideración era sin duda tener experiencia como juez a tiempo parcial. 
atienda las demandas sociales ${ }^{64}$ y que al mismo tiempo adquiera perfiles «específicos» de acuerdo a la plaza que se vaya a cubrir.

5. El «buen carácter» ${ }^{65}$ adquiere mucho peso también como ingrediente necesario en un proceso de selección. Ahora bien, no puede ser completamente delimitado en su contenido. Debe ser premeditadamente ambiguo en sus contornos $^{66}$.

6. Cualquier buen proceso de selección debe estar comprometido con la «diversidad». La doctrina ha reconocido muy insistentemente la gran asignatura pendiente en esta materia de los jueces británicos. Kate Malleson habla de que especialmente en la Senior Judiciary la diversidad es el «gran talón de Aquiles». Diversidad que está pensando en mujeres, en personas de color, en minorías étnicas y raciales, en colectivos formados en universidades distintas de Oxford y Cambridge, en Solicitors y no siempre en prestigiosos Barristers, etc... Una de las fortalezas de la judicatura es la experiencia de vida que los jueces llevan a sus «decisiones», esta es una buena fortaleza de la legitimidad de los jueces.

Describir el modelo anterior (secret-sounding, tap on shoulder) significa también contextualizar una Judicatura que ha sufrido importantes cambios formales, estructurales y esenciales. La Judicatura inglesa ${ }^{67}$ individualista y convencida de que gran parte de la lucha y logros de la independencia judicial estribaba en esa tarea aislada del juez como un funcionario civil, único y sólo, concentrado en sus procesos judiciales y fallos ha cambiado.

Aquella tradicional visión se ha valorado desde muy diversas perspectivas, algunos autores encuentran que aquí reside el éxito de la independencia de la Judicatura inglesa, sin preocupaciones de ascender, de pensiones o edad de

64 Morison J., «Beyond merit. The new challenge for judicial appointments», Debating Judicial Appointments in an age of Diversity, op. cít., chapter 11.

65 Es interesante ver, el concepto clásico de buen comportamiento ya en el Texto constitucional más viejo del mundo actual, "Can a Supreme Court justice be forcibly removed from the bench? A quick civics lesson», The Washington Post 12 december 2015: «...Supreme Court Justice Antonin Scalia, whom my Washington Post colleague Robert Barnes called "the reigning champion of provocation at the high court», just stirred up another controversy with comments about why African Americans might be better off if they are not accepted into top colleges and universities but rather to "slower-track» schools where «they do well» (...)» La Sección primera del Artículo 3 de la Constitución de los Estados Unidos señala: "The Judicial power of the United States, shall be vested in one supreme Court, and in such inferior Courts as the Congress may from time to time ordain and establish. The Judges, both of the supreme and inferior courts, shall hold their Offices during good Behaviour, and shall, at stated Times, receive for their services a compensation which shall not be diminished during their Continuance in Office...»

66 «...Judges must also have moral courage, it is a very important judicial attribute, to make decisions that will be unpopular whether with politicians or the media, or indeed the public and perhaps most important of all, to defend the right to equality and fair treatment before the law of those who are unpopular at any given time indeed particularly those who for any reason are unpopular...», Judge, Diversity Conference Speech, 2009, http://www.judiciary.gov.uk/docs/speech/lcj-speech-diversity-conf.pdf;

67 Andrews N., «Judicial independence: The British Experience» in S. Shetreet and Forsyth C. (eds.), The Culture of Independence: conceptual foundations and practical Challenges, Leiden: Martinues Nijhoff, 2012; Blom-Cooper L., Dickson B. y Drewry G., (eds) The Judicial House of Lords 1876-2009, Oxford: Oxford University Press, 2009. 
jubilación, etc. Sólo concentrada en elaborar sentencias sólidas y justas. Pero algún otro sector crítico ha expuesto, que esa idiosincrasia sirvió para esconder muchos años «las cloacas de la incompetencia judicial, de la indolencia, ineficiencia, insensibilidad e ignorancia...» ${ }^{68}$

El Juez ha ido poco a poco cambiando la concepción que tiene de sí mismo, más consciente de su pertenencia a un cuerpo (el de la Judicatura), con un sentimiento corporativo vivo y, en cierta medida, comprometido con percepción de relaciones jerárquicas, de la dimensión y significado de la carrera o promoción, con sentido de cuerpo y preocupaciones comunes.

\section{A MODO DE CONCLUSIÓN: EL ACTIVO Y NOVEDADES DEL NUEVO MODELO INGLÉS JAC TRAS MÁS DE DIEZ AÑOS DE EXPERIENCIA}

No hay duda de que el cambio vivido tras la reforma de 2005 es, sin paliativos, ingente. La reforma constitucional británica de 2005 es un escalón más en la escalada de cambios que comenzó con la ECA European Communities Act de 1972, siguió con la Human Rights Act de 1998 y se rediseña ahora desde 2005 con la CRA, institucionalmente y conceptualmente. El modelo constitucional británico, tras el Brexit, es aún más incierto. Los principios clásicos de soberanía parlamentaria y rule of law siguen adaptándose. Un modelo difícil de entender porque junto a la complejidad de una constitución «normativa» no escrita, Bagehot hablaba de su esencia dinámica, viva y cambiante.

Tendremos un Poder Judicial «justo» si es, entre otras necesidades, independiente. Y la independencia se analiza desde muchos elementos, los procesos de selección de jueces es uno de los más decisivos.

1) La justicia como la mujer del César, no sólo debe ser independiente, debe parecerlo y, aún más, convencer de ello. No será confiable una justicia que no tiene apariencia de independencia e imparcialidad. Este debate estuvo en los orígenes de la Constitutional Reform Act de 2005, Bradley durante su tramitación en la Cámara de los comunes señaló: "the changes made by the Act as they affect the judiciary should be seen as strengthening the integrity of the judicial system, not as weakening it.» ${ }^{69}$

2) La Judicial Appointments Commission (JAC) propone-recomienda candidatos, pero la realidad confirma que este órgano prácticamente nombra a los Jueces.

68 Woolf L., «Judicial Independence not Judicial isolation», The Pursuit of Justice, Oxford University Press, Oxford 2008, págs. 165 y ss.

69 Bradley A., Constitutional Reform Act 2005, $5^{\text {th }}$ Report of Session 2005-06, Select Committee on the Constitution, House of Lords;»...It is more important than ever that the courts should be able to do justice in an even-handed and impartial manner. Ministers and the Government in general should not seek to blame the judges when the courts make decisions that are adverse to the wishes or policies of the Government. The changes made by the Act as they affect the judiciary should be seen as strengthening the integrity of the judicial system, not as weakening it.» 
Ello significa un cambio radical, una ruptura valiente y decidida del viejo modelo urdido en la sombra de «tap on shoulder y secret soundings...» El sistema nuevo desde 2006 apuesta por la transparencia y publicidad, por el rigor y el pluralismo, por mayor legitimidad y diversidad. Y aun así, es obvia la poca «representatividad» de la Judicatura británica de una sociedad fragmentada, inmersa en un oscuro proceso de cambios e incertidumbres propiciados, ahora también, por el Brexit.

3) Cualquier proceso de selección y nombramiento de jueces tiene un trasfondo «político», a medida que ascendemos en el escalafón y, por tanto, en la relevancia y jerarquía de los fallos judiciales, aquél ingrediente se hará más palpable y evidente. Obviarlo es un riesgo, peor aún un peligro. La mejor opción será identificarlo, regularlo y limitarlo. La Comisión de Venecia declara: «The mere existence of a high judicial council cannot automatically exclude political considerations in the appointment process... ${ }^{70}$ El viejo escenario previo a la reforma de 2005 mostraba una relación y cooperación entre la política y la independencia judicial basada en la opacidad, la tradición y el discreto acuerdo o convención. El nuevo marco ha diseñado una nueva separación de poderes que relaciona ejecutivo y poder judicial, especialmente en materia de nombramientos judiciales, mediante procedimientos formales y estructuras institucionales estables, delimitadas, públicas y transparentes. Todo ello implica procesos más largos y fragmentados, pero al mismo tiempo más controlables, públicos e independientes. ${ }^{71}$

4) Los procedimientos deben ser claros y transparentes. Deben desarrollarse «equilibradamente», esto es, apostando por el mérito, la capacidad, la pluralidad social, la representatividad del mundo de la Judicatura y la diversidad e igualdad de género.

5) ¿Concentrar en un mismo órgano nombramiento, ascenso, inspección y régimen disciplinario? ¿Es independiente? ¿Permite una apropiada y suficiente rendición de cuentas? Los nombramientos de la Alta Judicatura, constituyen actos con cierta naturaleza política, no pueden ser arbitrarios, no pueden estar carentes de motivación. Diversificar en órganos distintos es incrementar la independencia.

Un buen diseño de un proceso de nombramiento de jueces debería diversificar: a) Convocatoria pública, b) órgano de propuesta distinto a órgano de consultas $y$, distinto a órgano de nombramiento, c) procedimiento claro, sencillo, transparente, eficaz, eficiente, de naturaleza «predominantemente judicial» y auditable, no sólo judicialmente, sino también al estilo británico del concepto «accountability». Y, desde luego, d) voluntad propia en el candidato para solicitar

70 Op cit, pág. 5;

71 «...Judicial Independence is necessarily a political achievement. Because the principle of judicial independence is contextual and contested, we can only understand its place in the constitutional arrangements of the UK today by examining the ways in which politicians, judges and officials negotiate and renegotiate its precise meaning and its limits...», Graham G., Hazell R., Malleson K., O’brien P., op. cít., pp. 253 
la plaza vacante que se publica. Cuánto más plurales y convencidos sean los candidatos, más se fortalecerá el sistema, «...don't be shy apply...»

6) Los jueces deben ser representativos de toda la sociedad, y aún más si son «altos cargos de la judicatura». Deben estar legitimados por su mérito, por su especialización, por su experiencia, buen carácter y buen comportamiento... Pero también deben estar legitimados por su personal concepción política de la Justicia, sobre todo para ocupar ciertos cargos o puestos dentro de la Judicatura que no sólo requieren de «magníficos expertos en derecho o brillantes conocedores de la jurisprudencia nacional e internacional», sino de otras habilidades y competencias que son las mismas que han justificado que no son cargos de nombramientos reglados, sino que son cargos de naturaleza discrecional.

Esto es lo que una Justicia independiente debe someter a la «luz y taquígrafos». Esta parte del nombramiento de los jueces, debe hacerse de manera pública y transparente: abundando en las exigencias de la plaza a cubrir (Jobs descriptions), cambiando las conversaciones secretas por documentos públicos que informan y justifican las recomendaciones de candidaturas, diseñando procesos con actores perfectamente reconocibles e identificables que permita en todo momento cierta rendición de cuentas.

7) Principios como «administración de la justicia en nombre el pueblo.», «los jueces fiel reflejo de la sociedad que conocen bien», son descuidados y convertidos en papel mojado, si los procedimientos de nombramiento no presentan cifras equiparables de hombres y mujeres en todos los niveles jerárquicos de la carrera judicial, si no existen distintas «sensibilidades»y «políticas de la justicia» en los jueces nombrados. (Eso en el modelo inglés se denomina BAME, Black people, and African minorities ethnics, que no sólo premian el pack «Oxbridge», esto es Juristas que proceden de Oxford y Cambridge, no sólo prestigiosos Barrister sino también más modestos Solicitors).

Gran parte de las reformas nacen bajo el paraguas de la regeneración democrática, en estas páginas en concreto del Poder Judicial y de la lucha frente a la politización de la justicia. La política de la Independencia Judicial no es, en absoluto, la politización de la justicia.

En el Reino Unido desde 2005, lo «político» está y se le espera. Toda la Constitutional Reform Act responde a la lucha e incesante búsqueda de la política de la independencia judicial. Sin duda será una conquista «política» el logro de la ansiada independencia judicial.

"...It is true that the post-2005 processes managed by the JAC, are now much more transparent than the traditional «tap on shoulder» approach associated with the Lord Chancellor's Department, but inevitably all of the most important interactions still occur out of sight and bebind closed doors... ${ }^{72}$

72 Graham G., «Judging the JAC. How much influence over judicial appointment is too much?» in Graham Gee and Erika Rackley, Debating Judicial Appointment in Age of Diversity, Routledge 2017. 
TITLE: The British model of judicial appointments

AвSTRACT: This paper studies the Constitutional Reform Act published in the 2005 in United Kingdom. This important reform means a deep constitutional change in an unwritten constitution model. The first part shows, critically, the old model explaining how the judges were appointed. The second part analyses the new model in which the most relevant role is played by the Judicial Appointments Commission, this new public body designed as recommendation body appoints the Judiciary in United Kingdom and it's being representative of the deepest change amid the classical concept of Judicial independence. More than ten years before the JAC's creation, important inputs could be commented.

RESUMEN: La ley de reforma constitucional de 2005 en el Reino Unido ha significado un cambio constitucional sin precedentes. Estas páginas analizan el modelo anterior a la reforma aludida, el contenido de esta reforma y sus importantes efectos en el Poder Judicial. El viejo sistema es descrito y comentado y después se exponen los principales contenidos de la reforma, centrándose en la creación de la JAC la Judicial Appointments Commission que es órgano público creado para nombrar a la Judicatura del Reino Unido. Por último se analizan los efectos positivos y negativos de un nuevo modelo que sin duda ha rediseñado el poder judicial en este país.

KEY WORDS: Judicial independence, procedures to appoint judges, constitutional reform, new model of separation of powers, constitutional reform, merit, accoutabiltiy, diversity.

Palabras Clave: Independencia Judicial, procesos de nombramientos de Jueces, separación de poderes, reforma constitucional, mérito, rendición de cuentas y diversidad.

FECHA DE RECEPCIÓN: 10.12.2018

FECHA DE ACEPTACIÓN: 29.07.2019 